\title{
Key Indicators of success or survival for clinical performance of fixed partial denture
}

\section{Lim Ghee Seong and Lee Wei May}

\section{KEYWORDS}

Fixed partial dentures, longevity, success, survival.

\begin{abstract}
When fixed partial dentures (FPDs) are being suggested to patients, the frequent inquiry by patients is the anticipated longevity and length of service. Previous reports have provided limited information on the accurate measurements of good clinical outcome and the length of good years in service. This confuses the clinicians as well as the patients in determining the treatment of choice. In the present article, the indicator of 'success' and 'survival' will be discussed in determining the longevity of various FPDs such as conventional, resin bonded and implant retained. After reviewing the articles, it is good if the indicator of 'success' can be used as an indicator of longevity and good clinical outcome. Besides that, studies with at least 10 years of observation are probably of higher evidence for longevity of restorations.
\end{abstract}

\section{INTRODUCTION}

For the past few decades, the availability of dental materials with improved properties and the introduction of new treatment modalities in fixed partial denture (FPD) like implant-retained prostheses have revolutionized dentistry in terms of teeth replacement therapy. Consequently, both the dentist and the patient expect high clinical performance restorations, which are simple to apply clinically, high durability, able to improve masticatory function, aesthetic and cost effective in the long-term. For that reason, the measurement of the longevity (survival) of both, there are many studies using either 'success' or

Department of Restorative Dentistry, Faculty of Dentistry, University of Malaya, Kuala Lumpur, Malaysia

*Correspondence: g.s.lim@um.edu.my 'survival' as the measurement or indicator of longevity for restorations. Survival was defined as FDP remaining in situ with or without modification and success was defined as the FDPs remaining in situ free of all complications over the entire observation period [1]. However, studies that mention which is more accurate in prediction of clinical outcome is sparse or non-existent. Therefore, the objective of this article is to study the indicators that can measure accurately the longevity of the restorations and good clinical outcome.

\section{CLINICAL PERFORMANCE OF FPD}

FPD has been successfully used as teeth replacements for many decades. It has taken many designs and forms such as conventional, adhesive (resin bonded) and implant-retained FPD. The decision on treatment modality by dental health professional (DHP) is mainly based on the long-term 
clinical data such as the survival data. There are only a few high-quality longitudinal studies being reported on the survival/success of the FPD and its' abutment teeth [2-6]. Ideally, the DHP should decide on the best treatment options based on well-performed systematic reviews. In other words, the systematic reviews should review the publications which are yielding high level of evidence e.g. randomized clinical control trials (RCT) [1, 7-9] However, it is difficult to obtain the data from randomized clinical control trials that compared the survival rate of different types of FPD, as prospective controlled trials with randomized treatment procedures may associate with ethical issues [9]. Therefore, most of the longitudinal systematic reviews reported on FPD survivals are based on lower level of evidence, observational studies like prospective and retrospective studies [9-11]. Besides that, the different ways in defining the clinical outcome, clinical and technical procedure and follow-up period may complicate the comparison of the clinical performance between different types of FPD $[12,13]$. Long-term studies with observational period of 10 years or more will provide a better insight into the longevity of the FPD, by providing meaningful interpretation of the survival, complications and failures. However, the downside of it will be relatively high dropout rate where many patients are unable to return for follow-up appointment due to health issue and death [14].

\section{DEFINITION OF SUCCESS, SURVIVAL, COMPLICATIONS AND FAILURES OF ABUTMENT TEETH AND FPD}

\section{CONVENTIONAL FPD}

Conventional tooth-supported FPDs alone have various designs and forms. In order to measure its clinical performance, the definition of success, survival and failure of both the abutment teeth and the prostheses itself are important. Tan et al. 2004[9] in their study defined survival as any FPD that was in situ at the examination visit irrespective of its condition. In other words, as long as the FPD stayed inside the mouth and did not require remaking, it is considered as 'survived'. From the meta-analysis of their systematic review [14] the conventional FPD yielded $89.1 \%$ of survival rate which was similar to other meta-analyses $[2,15]$. In recent systematic review of survival rates on multiple FPDs, 5 years survival rate ranging from $86 \%$ to $94 \%$ was observed according to types of materials namely metal ceramic FDPs, reinforced glass ceramic FPDs and densely sintered zirconia FPDs [1]. Meanwhile, success was defined as any
FPD that remained unchanged or free of all complications and did not require any intervention over the observation period. The estimated 10-year success rate of FPDs was $71.1 \%$. This low success rate was due to high occurrence of periodontal disease and secondary caries to the abutment that lead to the FPD failure [14]. FPD treatment was known to cause both the biological complications which were related to the abutment tooth for examples, caries, pulp necrosis and periodontal disease. It can also involve technical complications like loss of retention or abutment tooth and material related fractures ie., fractures of framework or veneer. Caries can occur on the abutment tooth, not leading to loss of FPD but requiring some repair or leading to FPD loss.[14] The 10-year survival risk for caries on abutment teeth were $9.5 \%$, however only $2.6 \%$ of FPD were lost due to caries [14]. While preparing the abutment teeth to receive FPD, the it may become non-vital because of the mechanical trauma inflicted and various noxious stimulus on the pulp through the open dentinal tubules [14]. In some studies, pulp necrosis was diagnosed based on the presence of periapical radiolucency [14, 16-18]. The 10 -year risk for loss of abutment vitality was $10 \%$, therefore it is recommended to monitor closely the vitality of the abutment teeth especially those with extensive preparation $[14,19]$. Periodontal pathology like recurrent periodontitis leading to loss of FPD was rare (0.5\%) [14]. Study have shown that those abutment teeth with restoration margin that had been placed subgingivally were more susceptible to periodontal disease compared to control teeth and restorations with supragingival margin [14, 18]. The highest 10-year risk for technical complications were loss of retention (6.4\%), followed by failure due to fracture of abutment tooth (2.1\%) [14]. Material complications including fractures of the framework, veneers amounted to $3.2 \%$ [14].

\section{RESIN-BONDED BRIDGE}

Resin-Bonded Bridge (RBB) has been one of the advancements in modern dentistry, with the advantages of tooth structure conservation and reversibility compared to conventional FPD. Over the past 20 years, it has evolved rapidly from initially being used as periodontal splint with perforated cast to those cement retained non perforated cast [20]. The huge variations in technique, clinician skill and patient selection were known to affect success/survival of the RBB [12, 20]. Initially, Creugers et al. 1997 [21] defined survival at two levels, the RBB was considered as completely survived when there was no loss of 
retention during the observation period either by the observer or by the patient; if there was loss of retention in one occasion and was treated successfully by rebonding the original RBB with no further debonds occurred, the RBB was considered as functionally survived. 10 years later in a systematic review conducted by Pjetursson et al.2008 [11] survival was defined as the RBB remaining in situ with/without modification for the follow-up period, which means it was considered survived, as long as the original RBB was able to rebond (with / without interventions) to the abutments without remaking it. While they defined success as an RBB being free of all complications (biological and technical) over the entire follow-up period. The reported survival rates of RBB were vary widely between studies, ranging from $74 \%-95 \%$ $[22,23]$ due to difference in the factors that affect the success and also difference in follow-up time. Pjetursson et al.2008 [11] mentioned a mean observation period of at least 5 years would provide a more accurate and meaningful interpretation of survival rate. In the systematic review, they reported the summary of estimation for the RBB survival after 5-year was $87.7 \%$, while 10-year survival was dropped to $65 \%$ [11]. An updated version of the same study was conducted in 2017 [8] reported estimated survival of resin bonded bridges of $91.4 \%$ after 5 years and $82.9 \%$ after 10 years. Biological and technical complications which would lead to the failure of RBB were not reported routinely in the studies [11]. Djemal et al,1999[24] defined failure as any significant complications related to the $\mathrm{RBB}$ that require remedial intervention or remake. Thus, debonding of RBB even once was considered failure, but caries on the abutments which were not related to retainer margin, were not regarded as failure. In the same study, they reported $27.88 \%$ of the RBB will experience failure [24]. Pjetursson et al, 2007[25] classified the complications -occurred on the RBB into two, biological and technical. Biological complications intended in this case are caries and recurrent periodontitis. While debonding (loss of retention) and material complications like framework and veneer fractures are considered as technical failure, debonding of RBB from abutment teeth is the most frequent technical complication with an estimated rate of $15 \%$ over 5-year observation period, RBBs with zirconia framework and RBBs with one retainer tooth showed the highest survival [8].

\section{IMPLANT-RETAINED FPD}

The use of osseointegrated implants to support prosthetic reconstructions such as FPD has gained popularity as one of the treatment modalities in teeth replacement. The ability to restore missing teeth without damaging its adjacent teeth and avoiding the inconvenience of bulky acrylic dentures were among its advantages over other fixed prosthodontics options. Both the patients and their dentist perceive implant treatment as troublefree tooth replacement, but its evidence is still lacking. Although it is believed that implant fixtures have good success rate and longevity (survival rate $>90 \%$ ) [26], but the restorations built up on the fixture can develop problems which are often underestimated [27]. Systematic reviews reported survival rate for implant-retained FPD after 5-year as $95.4 \%$ and $92.8 \%$ after 10 -year [28], similar to an updated similar study which reported 93\%-98\% survival rate over 5 years observation [29]. Survival of implant retained FPD was defined as both implant and FPD present in the mouth regardless of biological and/or technical complications while success was defined as being free of all these complications over the entire observation period.[30] Pjertusson et al [31] reported after 10year survival estimation was $86.7 \%$, while after 5 year success estimation was $61.3 \%[10,31]$. This means that, $38.7 \%$ of the patients will experience minor or major complications in the first 5 years after implantation [10]. Implant-retained prosthesis may experience different forms of complications as described by Pjetursson et al in Table 1.

Table 1. Cumulative 5-years complication on implant-supported reconstructions (Pjetursson et al. 2007) [4].

\begin{tabular}{|l|c|}
\hline Complication type & Complication Rate (\%) \\
\hline Soft Tissue injury & 8.6 \\
\hline Veneer Fracture & 11.9 \\
\hline $\begin{array}{l}\text { Ceramic } \\
\text { Chipping/Fracture }\end{array}$ & 8.8 \\
\hline Loss Of Retention & 5.7 \\
\hline $\begin{array}{l}\text { Abutment or Occlusal } \\
\text { Screw Loosening }\end{array}$ & 5.6 \\
\hline $\begin{array}{l}\text { Fracture of } \\
\text { Abutment/Occlusal } \\
\text { Screws }\end{array}$ & 1.5 \\
\hline Framework Fracture & 0.7 \\
\hline Implant Fracture & 0.5 \\
\hline
\end{tabular}


Traditionally, the options for tooth replacement would have been tooth-supported restorations. Since the introduction of implant-supported FPD, the role of conventional FPD has been somewhat questioned. Recently, there has been a series of systematic reviews comparing the long term clinical performance of tooth-supported restorations and implant-supported restorations (Table 2) [11, 25, 27]. The term ' long-term' has been defined as an observation period of at least 5 years [10]. Pjetursson et al. 2007 [25] has reported survival rate after 10 years of function, for conventional was $89.2 \%, 80.3 \%$ for cantilever, $65 \%$ for resin bonded FPD, and $86.7 \%$ for implant-supported FPD. The RBB showed the lowest survival rate after 10 years of functioning. Patients with implant-supported FPD experienced the highest complication rate (38.7\%) despite the relatively high survival rates.
This is compared with $15.7 \%$ for conventional FPD and $12.3 \%$ for RBB. The systematic review also reported that, the most frequent occurring complications for conventional FPD were biological complications like secondary caries and loss of pulp vitality due to mechanical trauma. For RBB, technical complications like debonding (loss of retention) were the more frequent. For implantsupported FPD, the most frequent technical complications were fracture of the veneer material (ceramic fractures or chipping) which can be up to $14 \%$. In comparison with tooth-supported FPD, only $3.2 \%$ of veneer material fractured during the 10 years period [25] This difference is due to the lack of proprioception and resiliency of implantsupported FPD which were normally provided by the periodontal ligament around the teeth [32].

Table 2. Comparison of clinical performance of tooth supported and implant supported restoration (Adapted from Pjetursson 2007,2008) [4,7].

\begin{tabular}{lcccc}
\hline Meta-analysis & $\begin{array}{c}5 \text { years } \\
\text { Survival (\%) }\end{array}$ & $\begin{array}{c}10 \text { years } \\
\text { Survival (\%) }\end{array}$ & $\begin{array}{c}5 \text { years } \\
\text { Success (\%) }\end{array}$ & $\begin{array}{c}\text { Complication } \\
\text { at 5 years (\%) }\end{array}$ \\
\hline Conventional tooth-supported FPD & 93.8 & 89.2 & 84.3 & 15.7 \\
Cantilever FPD & 91.4 & 80.3 & 79.4 & 20.6 \\
Resin Bonded FPD & 87.7 & 65 & $\mathrm{NA}$ & 12.3 \\
Implant-supported FPD & 95.2 & 86.7 & 61.3 & 38.7 \\
\hline
\end{tabular}

\section{COMPARISON OF CLINICAL PERFORMANCE BETWEEN ALL CERAMIC, ZIRCONIA CERAMIC AND METAL CERAMIC IN SINGLE AND MULTIPLE UNIT FDP}

As the demand for aesthetic in restorations grow stronger, the pursuit for the best material that matches the natural tooth color becomes greater. This has led to the development of tooth colored material like ceramic and zirconia. Ceramic alone has a few developments, from feldspathic, alumina, to lithium disilicate. Each has its own strength and weakness. Zirconia is well known for its strength besides providing acceptable aesthetic and over the years there are many studies that show these promising properties that enables it to be used in implant prosthodontics, both in single crowns and multiple unit FDPs [7, 29].
Table 3. Comparison of the 5 years survival rate between different ceramics, zirconia and metal ceramic for single or multiple unit tooth and implant supported FPDs

\begin{tabular}{|l|l|l|l|}
\hline & Zirconia & Ceramics & $\begin{array}{l}\text { Metal } \\
\text { Ceramics }\end{array}$ \\
\hline $\begin{array}{l}\text { Single Unit } \\
\text { FPD } \\
\text { (implant } \\
\text { [29]/tooth } \\
\text { supported } \\
\text { [30]) }\end{array}$ & $97.6 \%$ & $\begin{array}{l}\text { Litium } \\
\text { disilicate } \\
-96.6 \%\end{array}$ & $98.3 \%$ \\
Alumina \\
Multiple \\
$\begin{array}{l}\text { Unit FDP } \\
\text { (tooth } \\
\text { supported) }\end{array}$ & $90.4 \%$ & $\begin{array}{l}\text { Feldspathic } \\
-89.6 \%\end{array}$ & $94.4 \%$ \\
\hline & & Alumina & \\
\hline
\end{tabular}


With reference to Table 3, the survival rate for all three materials used for constructing single unit FPD had better performance compared to when they were used in multiple units FPD. However, there are studies $[29,30]$ using survival rate to measure the clinical performance and only of 5 years observation time.

\section{CONCLUSION}

Treatment planning in prosthodontics should be based on evidence and it is even better if it is supported by high-quality systematic reviews which provide a reliable source of evidence. Therefore, judging from the survival and success rate of different types of FPD, planning of prosthetic rehabilitation should preferably include conventional FPD if there were suitable abutment teeth or implant-supported FPD in ideal conditions of its placement. RBB will only be considered in certain anatomical area or with certain indicating factors. Therefore, it would be good to use 'success' as an indicator for good clinical outcome and longevity of FDPs to avoid confusion and easy comparison for all FPDs.

\section{ACKNOWLEDGEMENT}

The authors would like to thank Dr Robert Walter Wassell from Newcastle University, United Kingdom for the advises and guidance in writing this paper.

\section{DECLARATION OF INTEREST}

The authors report no conflicts of interest. The authors alone are responsible with the content of this article.

\section{REFERENCES}

1 Pjetursson, B.E., et al., All-ceramic or metal-ceramic tooth-supported fixed dental prostheses (FDPs)? A systematic review of the survival and complication rates. Part II: Multiple-unit FDPs. Dental materials, 2015. 31(6): p. 624-639.

2. Scurria, M.S., J.D. Bader, and D.A. Shugars, Meta-analysis of fixed partial denture survival: prostheses and abutments. J Prosthet Dent, 1998. 79(4): p. 459-64.

3. Pelaez, J., et al., A four-year prospective clinical evaluation of zirconia and metal-ceramic posterior fixed dental prostheses. International Journal of Prosthodontics, 2012. 25(5).

4. Tartaglia, G.M., E. Sidoti, and C. Sforza, Seven-year prospective clinical study on zirconia-based single crowns and fixed dental prostheses. Clinical oral investigations, 2015. 19(5): p. 1137-1145.

5. Brägger, U., et al., Complication and failure rates of fixed dental prostheses in patients treated for periodontal disease. Clinical oral implants research, 2011. 22(1): p. 70-77.

6. Solá-Ruiz, M.F., et al., Survival rates of a lithium disilicate-based core ceramic for three-unit esthetic fixed partial dentures: a 10-year prospective study. International Journal of Prosthodontics, 2013. 26(2).

7. Pjetursson, B.E., et al., A systematic review of the survival and complication rates of zirconia-ceramic and metalceramic single crowns. Clinical oral implants research, 2018. 29: p. 199-214.

8. Thoma, D.S., et al., A systematic review of the survival and complication rates of resin-bonded fixed dental prostheses after a mean observation period of at least 5 years. Clinical oral implants research, 2017. 28(11): p. 1421-1432.

9. Tan, K., et al., A systematic review of the survival and complication rates of fixed partial dentures (FPDs) after an observation period of at least 5 years: III. Conventional FPDs. Clinical oral implants research, 2004. 15(6): p. 654666.

10. Pjetursson, B.E., et al., A systematic review of the survival and complication rates of implant-supported fixed dental prostheses (FDPs) after a mean observation period of at least 5 years. Clin Oral Implants Res, 2012. 23 Suppl 6: p. 22-38.

11. Pjetursson, B.E., et al., A systematic review of the survival and complication rates of resin-bonded bridges after an observation period of at least 5 years. Clin Oral Implants Res, 2008. 19(2): p. 131-41.

12. Creugers, N.H. and M.A. Van 't Hof, An analysis of clinical studies on resin-bonded bridges. J Dent Res, 1991. 70(2): p. 146-9. 
13. Reitemeier, B., et al., A prospective 10-year study of metal ceramic single crowns and fixed dental prosthesis retainers in private practice set tings. The Journal of prosthetic dentistry, 2013. 109(3): p. 149-155.

14. Tan, K., et al., A systematic review of the survival and complication rates of fixed partial dentures (FPDs) after an observation period of at least 5 years. Clin Oral Implants Res, 2004. 15(6): p. 654-66.

15. Creugers, N.H., A.F. Kayser, and M.A. van 't Hof, A meta-analysis of durability data on conventional fixed bridges. Community Dent Oral Epidemiol, 1994. 22(6): p. 448-52.

16. Jokstad, A. and I.A. Mjor, Ten years' clinical evaluation of three luting cements. J Dent, 1996. 24(5): p. 309-15.

17. Palmqvist, S. and B. Swartz, Artificial crowns and fixed partial dentures 18 to 23 years after placement. Int J Prosthodont, 1993. 6(3): p. 279-85.

18. Reichen-Graden, S. and N.P. Lang, Periodontal and pulpal conditions of abutment teeth. Status after four to eight years following the incorporation of fixed reconstructions. Schweiz Monatsschr Zahnmed, 1989. 99(12): p. 13815.

19. Bergenholtz, G. and S. Nyman, Endodontic complications following periodontal and prosthetic treatment of patients with advanced periodontal disease. J Periodontol, 1984. 55(2): p. 63-8.

20. Hussey, D.L. and G.J. Linden, The clinical performance of cantilevered resin-bonded bridgework. J Dent, 1996. 24(4): p. 251-6.

21. Creugers, N.H., R.J. De Kanter, and M.A. van 't Hof, Long-term survival data from a clinical trial on resin-bonded bridges. J Dent, 1997. 25(3-4): p. 239-42.

22.Zalkind, M., P. Ever-Hadani, and N. Hochman, Resin-bonded fixed partial denture retention: a retrospective 13year follow-up. J Oral Rehabil, 2003. 30(10): p. 971-7.

23. Yap, A.U. and A.N. Stokes, Resin-bonded prostheses. Quintessence Int, 1995. 26(8): p. 521-30.

24. Djemal, S., et al., Long-term survival characteristics of 832 resin-retained bridges and splints provided in a postgraduate teaching hospital between 1978 and 1993. J Oral Rehabil, 1999. 26(4): p. 302-20.

25. Pjetursson, B.E., et al., Comparison of survival and complication rates of tooth-supported fixed dental prostheses (FDPs) and implant-supported FDPs and single crowns (SCs). Clin Oral Implants Res, 2007. 18 Suppl 3: p. 97-113.

26. Cohn, S.A., Treatment choices for negative outcomes with non-surgical root canal treatment: non-surgical retreatment vs. surgical retreatment vs. implants. Endodontic Topics, 2005. 11(1): p. 4-24.

27. Bartlett, D., Implants for life? A critical review of implant-supported restorations. J Dent, 2007. 35(10): p. 768-72.

28. Pjetursson, B.E., et al., A systematic review of the survival and complication rates of fixed partial dentures (FPDs) after an observation period of at least 5 years: I. Implant-supported FPDs. Clinical oral implants research, 2004. 15(6): p. 625-642.

29. Sailer, I., et al., A systematic review of the survival and complication rates of zirconia-ceramic and metal-ceramic multiple-unit fixed dental prostheses. Clinical oral implants research, 2018. 29: p. 184-198.

30. Simonis, P., T. Dufour, and H. Tenenbaum, Long-term implant survival and success: a 10-16-year follow-up of non-submerged dental implants. Clin Oral Implants Res, 2010. 21(7): p. 772-7.

31. Pjetursson, B.E., et al., A systematic review of the survival and complication rates of fixed partial dentures (FPDs) after an observation period of at least 5 years. Clin Oral Implants Res, 2004. 15(6): p. 625-42.

32. Linkevicius, T., et al., Veneer fracture in implant-supported metal-ceramic restorations. Part I: Overall success rate and impact of occlusal guidance. Stomatologija, 2008. 10(4): p. 133-9.

33. Sailer, I., et al., All-ceramic or metal-ceramic tooth-supported fixed dental prostheses (FDPs)? A systematic review of the survival and complication rates. Part I: Single crowns (SCs). Dental Materials, 2015. 31(6): p. 603-623.

License Information: This work is licensed under a Creative Commons Attribution 